University of Louisville

ThinkIR: The University of Louisville's Institutional Repository

College of Arts \& Sciences Senior Honors

Theses

College of Arts \& Sciences

$5-2013$

\title{
Television and depression.
}

Rachel Marie Cunningham

University of Louisville

Follow this and additional works at: https://ir.library.louisville.edu/honors

Part of the Psychology Commons

\section{Recommended Citation}

Cunningham, Rachel Marie, "Television and depression." (2013). College of Arts \& Sciences Senior Honors Theses. Paper 52.

http://doi.org/10.18297/honors/52

This Senior Honors Thesis is brought to you for free and open access by the College of Arts \& Sciences at ThinkIR: The University of Louisville's Institutional Repository. It has been accepted for inclusion in College of Arts \& Sciences Senior Honors Theses by an authorized administrator of ThinkIR: The University of Louisville's Institutional Repository. This title appears here courtesy of the author, who has retained all other copyrights. For more information, please contact thinkir@louisville.edu. 


\section{Television and Depression}

\section{By}

Rachel Marie Cunningham

Submitted in partial fulfillment of the requirements

for Graduation summa cum laude

and

for Graduation with Honors

from the Department of Psychological and Brain Sciences

University of Louisville

March 2013 


\begin{abstract}
The purpose of this study was to analyze the relationship of mood and depressive symptoms with both the amount and type of television programming viewed. This study was also concerned with learning whether members of different genders and age groups are more or less likely to exhibit correlations between positive or negative mood and certain amounts and types of programs watched. The study addressed the following research questions: Question 1: What is the relationship between mood and amount of television viewing time? Question 2: What is the relationship between mood/depression and different types of programming, and is the same relationship exhibited across different age groups and genders? Participants completed questionnaires containing questions concerning their physical activity, depressive symptoms, daily mood ratings, and daily television viewing records. There were no significant relationships found between daily negative affect and daily viewing or between increased time watching each category of programming and higher rates of depressive symptoms. However, significant positive correlations were found between time spent watching television and positive mood for days $1,3,4,6$, and 7 . Age, sex, television watching, and physical activity were not found to significantly predict levels of depressive symptoms. While it is impossible to determine causation from the present study, these findings lend partial support to the idea that television viewing could serve the purpose of coping with negative moods.
\end{abstract}

Keywords: television, depression, mood 


\section{Television and Depression}

The topic of this study is the link between television viewing habits and the manifestation of depressive symptoms. Depression is a serious problem, and understanding how the activities we choose might affect our risk for developing depressive symptoms is crucial. Numbers indicate that of 235,067 adults, 9.1\% meet the requirements for diagnosable depression (cdc.gov, 2011). On their website, the CDC lists some of the consequences of depression, which include the worsening of other conditions, such as diabetes, obesity, cancer, asthma, and arthritis. Similarly, unipolar depressive disorders are cited as being the largest cause of disability, as well as being associated with increased mortality risk (Ohayon, 2007). Also listed by the CDC are some common risk factors for developing depression, which include being non-white, being female, and being middle-aged (cdc.gov, 2011). Similarly, other studies have found that women are more likely to develop depression than are men. In the study conducted by Ohayon, a higher rate of depression was found in women (5.8\%) than in men (4.6\%). A higher rate of major depressive disorder was found in those in the 45-54 age range, as well. Unipolar depressive disorders are cited by Ohayon as being the largest cause of disability and associated with increased mortality risk. Because depression so clearly has a negative impact on life and wellbeing, anything that will lead us to a greater understanding of the nature of depression, and especially its association with daily activities, may be useful for developing more effective treatments.

According to the well-known Nielsen ratings, women watch more television than men. Older Americans (65 and older) watch more television than younger Americans (35-49), and about twice as much as teenagers (Blog.nielsen.com, n.d.). In light of the cited gender and age differences in the prevalence of depressive disorders, these characteristics of television watching 
become much more interesting. My interest in proposing this study was to examine whether television-watching and depressive symptoms are in fact correlated. As stated above, there is a general consensus that women are more prone to depression. However, a study reported in Nursing Standard (Nursing Standard, 2009) claims that men are especially vulnerable to the depressive effects of increased television viewing. By contrast, Potts and Sanchez (1994) found that heavy rates of television viewing were not related to depression for the participants of their study. These conflicting findings inspired the present study, to examine whether television viewing is indeed related to depressive symptoms, as well as whether there are significant gender differences, both in quantity and quality of television consumed.

While patterns of correlations between amount of viewing and/or type of viewing and depressive symptoms are of interest and importance in all age groups, it will be especially interesting to note these patterns in older adults. There has not been a great deal of research conducted on the links between television and depression in older adults, and understanding these links more clearly could lead to the improvement of quality of life in a group that is susceptible to the negative effects of depression.

There is research that suggests that television and emotional experience are related. Several different views of the relevance of television in this area have surfaced, such as the idea that television is used by viewers for differing motives. For instance, Potts and Sanchez (1994) found that men tended to cite avoiding loneliness and getting away from others as their motives. Women, on the other hand, said that avoiding loneliness and escaping problems were their motives. One of the motives for depressed subjects for watching television was to "increase pleasurable experiences” and as a coping strategy for dealing with their depression. The researchers cited Rubin’s (1983) five motives for television use, which included passing time, 
entertainment, companionship, information, and escape. They found that television viewing typically can provide relief of the individual's depressive moods. However, viewing the news might aggravate these moods. Furthermore, the motives a depressed individual has for watching television may reflect their efforts to deal with their moods. For instance, depressed persons may gain a sense of control resulting from information obtained from news viewing. On the other hand, some may report that the negativity of the news content aggravates their depression, and some may even avoid watching the news.

Nguyen and colleagues (Nguyen, Wittink, Murray, \& Barg, 2008) found that older adults could perceive television in terms of depression and understand its differing functions. Subjects said that changes in viewing habits or lack of interest could help them identify depression in themselves or in others. Others said that watching television could aid in coping with depression. Some subjects cited television as a method of identifying depression in themselves or in others, others viewed television as a coping mechanism in terms of depression, and still others saw television as having the potential to exacerbate depression with its negative content. Some participants also said that television could be both helpful and harmful, helpful in coping with depression as well as in identifying it, and helpful in identifying depression, as well as having harmful consequences. Four participants even mentioned all three of these concepts. Another paradigm, the Uses and Gratifications Theory, has been cited by a couple of authors and also lends support to the idea that emotional needs determine television-watching motives. Sherry (2001) viewed media usage in terms of the Uses and Gratifications Theory, in which individual differences and understood needs determine motivations. He looked at the motives people have for using different forms of media, one of which is television. Sherry studied how the temperament of the individual plays a role in what children choose to watch and 
the emotional outcomes of their watching behavior. He, like Potts and Sanchez (1994), claimed that television viewing often serves as a means of mood management. Sherry points to the prevalence of situation comedies on television as support for his explanation. These programs could be used by depressed viewers to counter negative moods and function in terms of rigidity (containing few plot surprises) and low-task orientation (stimulating and maintaining attention). Although this study used temperament as one of its main variables, it again pointed to the idea that television is linked to certain moods and emotions.

Roe and Minnebo (2007) also used the Uses and Gratifications Theory when examining motives for watching television, this time in adolescents. They explained that, according to this theory, the degree of motivation an individual has for watching particular programming is related to how much it is fulfilling their needs. The main objective of this study was to test Elliott's (1974) assertion that media consumption may be explained by both social and psychological factors. The researchers also included gender and age as significant variables in their study. It was found that male subjects tended to use television as a method of mood management more often than did their female peers, and students typically watched television in order to lessen stress caused by strong effort at school and negative relationships with parents, among other problems. This study also lends support to the idea that mood and television are related.

A study conducted by Greenwood and Long (2009) examined how likely individuals in certain moods are to use different forms of media for entertainment purposes. They speculated that patterns of choosing specific media across positive and negative moods shed light on a person's typical regulation tendencies. The hypothesis was that difficulty regulating emotion and typically ruminating on negative events would be positively correlated with the likelihood of using entertainment media while in a negative mood state. They found that those who reported 
using media when in a negative mood were somewhat more likely to use it while in a positive mood, and vice versa. Boredom, however, was not found to be a predictor of media consumption when the individual was experiencing positive or negative emotions. They concluded that television viewing may fulfill relaxation needs when individuals feel disengaged from their environment, and that more television viewing may hinder the development of better methods of coping with boredom. The authors of this article stated that rather than being aligned with the uses and gratifications theory, their research is better explained by selective exposure and mood management theories. This provides an alternative perspective for understanding the link between individuals' media choices and states of mood.

Goodwin and colleagues (Goodwin, Intrieri, \& Papini, 2005) found that higher levels of daily perceived stress and a greater manifestation of depressive symptoms were positively correlated with more negative affect during TV watching. They concluded that television produces some desired affective experience for the older adults who voluntarily spent a significant amount of time watching TV. They concluded that TV was used to reduce negative affect and maintain an optimum level of affective arousal. However, the older adults in this study experienced their highest levels of both positive and negative affect when participating in productive activities. The authors cited Socioemotional Selectivity Theory (SST) as an explanation for the older adults' choice to watch television as a leisure activity. According to their application of this theory, older adults chose to watch television because they believed that it could help them avoid negative affect or heighten positive affect. At the end of the article, the authors cited television's importance in the maintenance of optimal emotional experience of older adults. 
While Lucas and colleagues (2011) found that each category of television-viewing time was positively correlated with the risk of developing depression, they also explored the effect of physical activity in conjunction with television on depression. They found that physical activity is usually replaced with television viewing. While acknowledging that the correlational nature of their study prohibits causal inference, they postulated that less time spent watching television, along with regular exercise, may contribute to a lower risk of depression. The findings of this project indicated that women who were physically active were less likely than less active women to spend at least 21 hours per week in front of the television. Furthermore, the researchers found that each category of television-viewing time was positively correlated with the risk of developing depression. Since physical activity may be a confound in the relationship between television watching and depressed mood, it is important to include a measure of physical activity in any investigation of the mood-television watching relationship.

\section{Hypotheses}

1. More television viewing time will be associated with lower positive and higher negative affect, evidenced in overall positive and negative mood ratings and total depressive symptoms. The PANAS mood scale scores and self-recorded television watching of each participant will be used to determine a correlation.

2. Different types of programming will also be associated with different levels of overall mood, for all age groups being studied. Although I will also be exploring the effect of other variables, such as age, gender, and physical activity, I will be arguing that higher levels of television viewing will be tied to higher rates of depressive symptoms, and different programs will have different effects on the rates of depressive symptoms exhibited. In line with my 
hypotheses, amount and type of television will serve as the independent variables, and the presence of depressive symptoms will serve as the dependent variable.

\section{Methods}

\section{Procedures}

I recruited prospective participants at social functions, extracurricular activities on campus, a community center, my neighborhood, and an undergraduate psychology course, in an attempt to include participants across a range of age groups from age 18 to 65 and above. Participants were given a questionnaire packet that included the following measures, and asked to return the packet after a week.

\section{Measures}

PANAS Mood Scale. The Positive and Negative Affect Schedule (PANAS; Watson et. al., 1988) was used to record the participants’ daily moods. The PANAS consists of 20 items pertaining to both positive affect and negative affect (10 each). Positive emotions are listed, such as interested, excited, strong, and enthusiastic, as well as negative emotions, such as irritable, ashamed, guilty, and hostile. Participants will be asked to indicate the extent to which they presently feel the emotion stated. Participants assign a number to each statement from the following Likert-type scale: Very Slightly or Not at All (1), A Little (2), Moderately (3), Quite a Bit (4), and Extremely (5). Since moods fluctuate, participants completed the mood scale each day they participated in the study.

The reliability of the PANAS is supported by a study conducted by Crawford and Henry (2004). They collected completed PANAS forms from 1,003 participants (537 females and 466 
males). The reliabilities were found by using Cronbach's alpha and were found to be .89 and .85 for positive and negative affect, respectively.

CES-D Depression Scale. The Center for Epidemiologic Studies Depression Scale (CESD; Radloff, 1977) consists of 20 items and serves to measure the prevalence of the participant's depressive feelings and behaviors within a week. Participants completed this measure once, on the first day of their participation. The scale includes statements such as, "I was bothered by things that usually don't bother me” and "My sleep was restless” are included, as well as more positive statements such as "I felt hopeful about the future” and "I enjoyed life.” Participants report how many times they have felt the corresponding statement within the past week according to the following scale: Rarely or none of the time (less than one day), Some or a little of the time (1-2 days), Occasionally or a moderate amount of time (3-4 days), and Most or all of the time (5-7 days).

The CES-D has been found to be reliable across a variety of age groups. It has been tested in both home interviews and those conducted in psychiatric settings (Radloff, 1977). The items are adapted from other previously validated depression scales. This fact contributes to its validity and the correlation of the CES-D with other depression self-report measures. The CESD Scale has been shown to possess high internal consistency and close correlation with other measures of depressive symptoms. This is evidenced by Radloff's study, in which adults in Kansas City, Missouri (1,173), and Washington County, Maryland (1,673), were randomly selected to complete interviews. The scale was found to be both reliable and valid across demographic variations within samples of the general adult population. In this study, the coefficient alpha was at least .80 within all demographic groups (age, sex, race, and education level). The CES-D does not constitute a clinical diagnosis; however, it is useful both in 
identifying individuals at risk of developing depression and/or needing treatment and in analyzing relationships between depression and other variables.

Physical Activity Scale. Participants were provided with a list of recreational activities, such as walking, hiking, jogging, biking, and gardening, and asked to indicate whether or not they participated in each activity and how many days and minutes per day they did so for each day of the week that they participated in the study. This scale is adapted from the work of Cooper and colleagues (2011).

Programming Categories. Participants were asked to record their time viewing the following types of programming: action, comedy, romance, horror, drama, local news, national news, documentary, educational, crafts, nature, reality, religious, sports, music, infomercials, home shopping, variety, and game shows. I devised these categories with some guidance from the Canadian Radio-television and Telecommunications Commission (Crtc.gc.ca, 2011).

\section{Results}

Sixty-two participants completed questionnaires concerning their depressive symptoms, physical activity, moods, and television watching. Participants included 22 men (35.5\%) and 39 women (62.9\%) ranging in age from 19 to 84 years of age. Twenty-four participants (38.7\%) were students. 24 (74\%) of participants were employed. Twenty (32.3\%) of respondents were married/in a civil union, 9 (14.5\%) were separated/divorced, 31 (50\%) were single/never married, and 2 (3.2\%) were widowed. Table 1 shows the means and standard deviations for the continuous variables. 
Table 1: Means and Standard Deviations of Continuous Variables

\begin{tabular}{lcc}
\hline Variable & Mean & Standard Deviation \\
\hline Age & 40.75 & 19.84 \\
Education Level & 13.88 & 3.30 \\
Positive Affect & 163.93 & 80.65 \\
Negative Affect & 97.23 & 66.67 \\
CES-D & 14.90 & 10.54 \\
Physical Activity & 1659.12 & 3026.80 \\
\hline
\end{tabular}

The first hypothesis, that more television viewing time would be associated with lower positive and higher negative affect, was not supported by these findings. As shown in Table 2, no significant relationships were found between daily negative affect (indicated by the total of PANAS negative items for each day) and daily viewing time.

Table 2: Correlations (PANAS Negative Daily Totals \& Total Daily Hours)

\begin{tabular}{lccc}
\hline & $\begin{array}{c}\text { Pearson } \\
\text { Correlation }\end{array}$ & Sig. (2-tailed) & N \\
\hline Total TV Day 1 & .057 & .658 & 62 \\
Total TV Day 2 & -.042 & .744 & 62 \\
Total TV Day 3 & .014 & .915 & 62 \\
Total TV Day 4 & .060 & .641 & 62 \\
Total TV Day 5 & .071 & .585 & 62 \\
Total TV Day 6 & .111 & .396 & 61 \\
Total TV Day 7 & .127 & .330 & 61 \\
\hline
\end{tabular}

On the other hand, as shown in Table 3, higher amounts of time spent watching television were positively associated with positive mood on days $1,3,4,6$, and 7. 
Table 3: Correlations (PANAS Positive Daily Totals \& Total Daily Hours)

\begin{tabular}{lccc}
\hline & $\begin{array}{c}\text { Pearson } \\
\text { Correlation }\end{array}$ & Sig. (2-tailed) & N \\
\hline Total TV Day 1 & $.553^{* *}$ & .000 & 62 \\
Total TV Day 2 & .247 & .053 & 62 \\
Total TV Day 3 & $.311^{*}$ & .014 & 62 \\
Total TV Day 4 & $.435^{* *}$ & .000 & 62 \\
Total TV Day 5 & .238 & .063 & 62 \\
Total TV Day 6 & $.454^{* *}$ & .000 & 61 \\
Total TV Day 7 & $.356^{* *}$ & .005 & 61 \\
\hline
\end{tabular}

* Correlation is significant at the 0.05 level (2-tailed).

** Correlation is significant at the 0.01 level (2-tailed).

My second hypothesis was that different types of programming would be associated with different levels of depressive symptoms for all age groups being studied. Significant correlations were not found between increased time watching each category of programming and higher rates of depressive symptoms, as indicated by CES-D score totals, as shown in Table 4. 
Table 4: Correlations (CES-D Totals \& Category Total Hours)

\begin{tabular}{lccc}
\hline & $\begin{array}{c}\text { Pearson } \\
\text { Correlation }\end{array}$ & Sig. (2-tailed) & N \\
\hline Action Total & .030 & .818 & 62 \\
Nature Total & -.132 & .305 & 62 \\
Comedy Total & .134 & .301 & 62 \\
Horror Total & -.018 & .888 & 62 \\
Drama Total & .025 & .847 & 62 \\
Local News Total & -.063 & .625 & 62 \\
National News Total & -.059 & .651 & 62 \\
Documentary Total & .012 & .927 & 62 \\
Educational Total & -.127 & .326 & 62 \\
Crafts Total & -.097 & .451 & 62 \\
Variety Total & -.040 & .760 & 62 \\
Reality Total & .117 & .366 & 62 \\
Religious Total & .036 & .779 & 62 \\
Sports Total & .012 & .928 & 62 \\
Music Total & .101 & .434 & 62 \\
Infomercials Total & .076 & .557 & 62 \\
Home Shopping Total & N/A & N/A & 62 \\
Game Shows Total & -.049 & .707 & .283 \\
Other Total & .139 & & 62 \\
\hline
\end{tabular}

To determine the combined relationship of age, sex, television watching, and physical activity with depressive symptoms, a multiple regression analysis with the CES-D as the dependent variable and the other variables as predictors was used. The overall multiple R was not significant: $R=.282, F(3,53)=1.522, p=.220$. That is, none of these variables was significantly related to depressed mood in this sample. 


\section{Discussion}

The purpose of this study was to explore the relationship between mood and amount of time spent watching television. I hypothesized that television watching would have an overall negative relationship with mood, that is, increased negative mood and decreased positive mood. In contrast with my first hypothesis, no significant correlations were found between negative affect (as indicated by the total PANAS negative scores) and total daily viewing hours. On the contrary, a positive correlation was found between total viewing hours and positive affect on days $1,3,4,6$, and 7 .

The findings also did not support my second hypothesis, in which I stated that the different program types would be associated with different levels of negative mood symptoms across all age groups. Higher levels of viewing were not associated with higher rates of depressive symptoms, and there were no differences in depressive symptom manifestation in terms of different categories of programs. The variables of age, gender, and physical activity did not significantly predict depression levels. On the other hand, significant positive correlations were found between the overall positive mood rating and the total viewing time for days $1,3,4$, 6 and 7.

This was a correlational study; therefore, it is impossible to determine causation, either of depressive symptoms or moods, from the positive findings. Additionally, the sample size is small, and more significant effects may have been found had it been larger. However, the results of this study are somewhat consistent with the findings of Goodwin and her colleagues (2005), as well as those of Greenwood and Long (2009). To some extent, both studies suggested that television viewing could serve the purpose of coping with negative moods. The results of the 
current study suggest that there is a relationship with positive mood and TV watching, but it is impossible to determine whether any of the participants had negative moods that were decreased or even erased as a consequence of watching specific types of programming. Future research could address this question by including a question concerning the purpose or motive behind the participant's television watching for that day, although participants might not have been able accurately to pinpoint their motives for watching television at that time. Motives may have differed throughout the day. This would have made the questionnaire more difficult and timeconsuming to complete, and possible that many participants would be discouraged by this. Further research with a more detailed methodology, such as monitoring moods before and after viewing, could help clarify the relationship between television and mood management.

Some of the participants in the study by Nguyen and colleagues (2008) said that changes in viewing habits can often serve as a signal of depression. Further analyses of the data would be needed to explore this possibility. Further research in this area could also shed some light on this possible relationship. If the participants in this study attempted and succeeded at using television as a coping mechanism to help alleviate their depressive symptoms, this would provide further support for the results of the Nguyen et al. study. If television viewing is used to regulate negative mood, individuals themselves could take a more proactive approach in recognizing their symptoms and pursuing intervention.

Another area of interest in the current study has to do with the "Other" category of television viewing. It is hard to say what participants meant when they chose this category. Participants did sometimes describe what they chose to designate as "Other." For instance, one participant wrote "soap operas" alongside his or her viewing time in that blank. Other responses for this category included cooking shows, cartoons, and Fox News. It would be interesting to 
know the types of programming that fell under this category and to study each of them separately if there were a larger sample

Another area of interest in the current study has to do with the "Other" category. It is hard to say what participants meant when they chose this category. Participants did sometimes describe what they chose to designate as "Other." For instance, one participant wrote "soap operas" alongside his or her viewing time in that blank. Other responses for this category included cooking shows, cartoons, and Fox News. It would be interesting to know the types of programming that fell under this category and to study each of them separately.

\section{Conclusion}

The results of this study do not support the idea that increased viewing time correlates positively with increased manifestation of depressive symptoms, nor to the relationship between particular categories of television viewing and depressive symptoms. The results instead indicate that increased television watching correlates positively with positive affect. For this reason, the results seem to lend partial support to the theory that viewing can serve the purpose of mood-management. Future research could use these results as a starting point for obtaining more detailed information concerning how television viewing may be used to regulate mood. For instance, researchers interested in further exploring this relationship might devise a method of measuring positive and negative affect both before and after subjects watch television for varying amounts of time. 


\section{References}

Centers for Disease Control (2011). An estimated 1 in 10 u.s adults report depression. (2011, March 31). Retrieved from http://www.cdc.gov/features/dsdepression/. Retrieved [October 15 2012].

Cooper, R., Kuh, D., Cooper, C., Gale, C.R., Lawlor, D. A., Matthews, F., Hardy, R., \& The Falcon And Halcyon Study Teams (2011). Objective measures of physical capability and subsequent health: A systematic review. Age and Ageing, 40, 14-23.

Crawford, J. R., \& Henry, J. D. (2004). The Positive and Negative Affect Schedule (PANAS): Construct validity, measurement properties and normative data in a large non-clinical sample. British Journal of Clinical Psychology, 43(3), 245-265.

Goodwin, P. E., Intrieri, R. C., \& Papini, D. R. (2005). Older adults. Activities, Adaptation, and Aging, 29(2), 55-72.

Greenwood, D. N., \& Long, C. R. (2009). Mood specific media use and emotion regulation: Patterns and individual differences. Personality \& Individual Differences, 46(5/6), 616621. doi:10.1016/j.paid.2009.01.002

Lucas, M., Mekary, R., Pan, A., Mirzaei, F., O'Reilly, É. J., Willett, W. C., Koenen, K., Okereke, O., \& Ascherio, A. (2011). Relation between clinical depression risk and physical activity and time spent watching television in older women: A 10-Year prospective follow-up study. American Journal of Epidemiology, 174(9), 1017-1027.

Nguyen, G. T., Wittink, M. N., Murray, G. F., \& Barg, F. K. (2008). More than just a communication medium: What older adults say about television and depression. Gerontologist, 48(3), 300-310. 
Ohayon, M. M. (2007). Epidemiology of depression and its treatment in the general population. Journal of Psychiatric Research, 41(3-4), 207-213. doi:10.1016/j.jpsychires.2006.10.006

Potts, R., \& Sanchez, D. (1994). Television viewing and depression: No news is good news. Journal of Broadcasting \& Electronic Media, 38(1), 79.

Radloff, L. (1977). The CES-D Scale: A self report depression scale for research in the general population. Applied Psychological Measurement, 1, 385-401.

Roe, K., \& Minnebo, J. (2007). Antecedents of adolescents' motives for television use. Journal of Broadcasting \& Electronic Media, 51(2), 305-315. doi:10.1080/08838150701304902

Sherry, J. L. (2001). Toward an etiology of media use motivations: The role of temperament in media use. Communication Monographs, 68(3), 274-288. doi:10.1080/03637750128065

Canadian Radio-television and Telecommunications Commission: Television program categories. (2011, April 11). Retrieved from http://www.crtc.gc.ca/canrec/eng/tvcat.htm

Watson, D., Clark, L. A., \& Tellegan, A. (1988). Development and validation of brief measures of positive and negative affect: The PANAS scales. Journal of Personality and Social Psychology, 54(6), 1063-1070.

[Web log message]. (2011, August 01). Retrieved from http://blog.nielsen.com/nielsenwire/online_mobile/american-video-habits-by-age-genderand-ethnicity/

Young men who watch a lot of television are prone to depression (2009). Nursing Standard, 23(29), 17. 